\title{
Evaluation of Face Support Pressure Prediction for Earth Pressure Balance (EPB) Tunnelling using Analytical and 3-Dimensional Finite Element Modelling
}

\author{
Fahmi Aldiamar ${ }^{1 *}$, Masyhur Irsyam² ${ }^{2}$ Bigman Hutapea ${ }^{2}$, Endra Susila² Desyanti $^{1}$ \\ ${ }_{1}^{1}$ Institute of Road Engineering, Ministry of Public Works, Jl A H Nasution No 264, Bandung 40294, Indonesia \\ ${ }^{2}$ Bandung Institute of Technology, Jl Ganesa No 10, Bandung 40132, Indonesia
}

\begin{abstract}
A shield tunnelling technique is usually selected using earth pressure balance or slurry methods for tunnel construction in urban areas with soft and saturated ground. Although shield tunnelling has many advantages, incorrect determination of face pressure could cause ground surface settlement or lifting during tunnel construction. Numerous approaches for determining face support pressure have been published internationally, but a suitability evaluation based on local ground conditions in Indonesia has not been conducted yet. The completion of Mass Rapid Transit Jakarta (MRTJ) tunnel construction project using the earth pressure balance method, along with its adequate data, has become a sample case of the effectiveness of each method to determine face support pressure. The study discussed in this paper aimed to determine the linear relationship between the calculated value and the actual measurement of face support pressure and to identify which method most closely represents the actual condition according to the MRTJ case study. An analytical approach using the limit equilibrium method and the numerical approach using Plaxis 3D were conducted, followed by statistical evaluation in the terms of coefficient of variation. The result shows that the limit equilibrium method is effective in predicting the mean value face support pressure and the upper and lower perimeters for tunnel construction, while the overall face support pressure result using the shell model of the finite element method are lower than the actual measured values. The result probably indicates the balance state condition at the tunnel face, and the additional $80 \mathrm{kPa}$ after the second phase of excavation could indicate the need for greater pressure for tunnel boring machine movement.
\end{abstract}

Keywords: Face support pressure; Finite element method; Mass rapid transit; Tunnels

\section{Introduction}

In urban areas, tunnel construction through soft and saturated ground requires special caution because unsuitable construction methods can disturb the surrounding infrastructures causing them to collapse. Under such conditions, shield tunnelling is usually selected using the earth pressure balance (EPB) method or slurry method. Both methods reduce the disturbance at the tunnel face and around the excavation area using a tunnel boring machine (TBM). Although shield tunnelling has many advantages, incorrect determination of face pressure could cause ground surface settlement or lifting during tunnel construction. Numerous analytical, empirical, and numerical approaches for 
determining face pressure have been published in international journals or in technical guidelines, but a suitability evaluation according to local ground conditions in Indonesia has not yet been conducted. The Mass Rapid Transit Jakarta (MRTJ) tunnel construction project was recently completed using the EPB method, and face pressure data according to earth pressure gauges, along with soil profile and the results from in situ and laboratory testing, are available as a sample case demonstrating the effectiveness of the limit equilibrium method and the 3-dimensional (3D) finite element method to determine the face support pressure. The study discussed in this paper aimed to determine the linear relationship between the calculated value and the actual measurement of face support pressure and to identify which method most closely represents the actual condition according to the MRTJ case study.

The EPB method is based on equilibrium between soil pressure and water pressure with jacking force applied on the cutterhead. A screw conveyor has the ability to adjust or control the face pressure during an excavation. For a tunnel constructed below the ground water level, the length of the screw conveyor must be designed to withstand hydrostatic pressure and transform water pressure into atmospheric pressure. An illustration of the EPB machine used in the MRTJ project is shown in Figure $1 \mathrm{a}$, and the position of the pressure gauge instrumentation is shown in Figure 1b. pressure gauges were installed to measure the soil pressure exerted on the cutterhead and to inform the machine operator as to whether the estimated pressures were still safe.

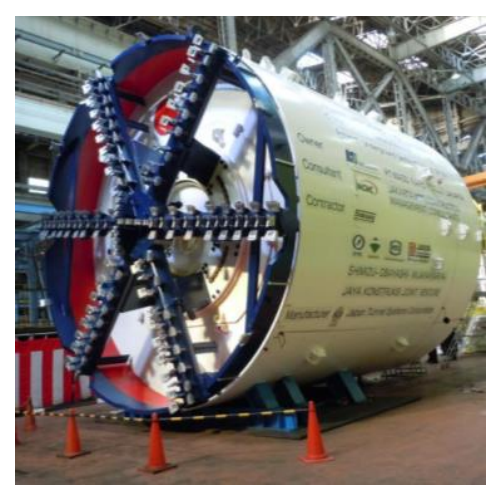

(a) EPB tunneling machine

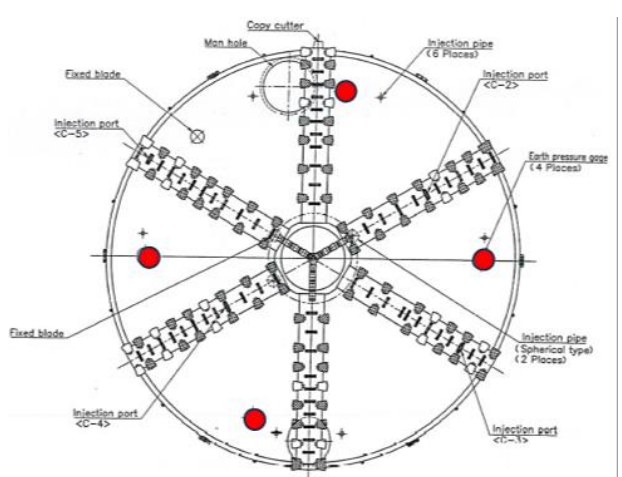

(b) Position of the earth pressure gauges

Figure 1 Illustration of an EPB tunnel machine and the position of the earth pressure gauges (SOWJ, 2015)

\section{Methods}

\subsection{Face Support Pressure Calculation}

According to the German Tunneling Committee (ITA-AITES, 2016), several methods can be used to determine face support pressure. Since they are simple and practical, limit equilibrium and limit state methods are usually used in the design phase based on the assumption that the ground stress distribution, which is influenced by the elevation of the ground water level and the unit weight of the soil, could indicate the need for supporting face pressure to prevent collapse.

In the limit equilibrium method, the failure mechanism basically refers to the support force divided by the acting force on the sliding wedge mechanism. The support force and soil shear strength act as stabilizing forces, while the sliding wedge weight and the load from the prism are defined as destabilizing forces. The equilibrium conditions are formulated on the sliding surface (Figure 2) in perpendicular and parallel directions. 


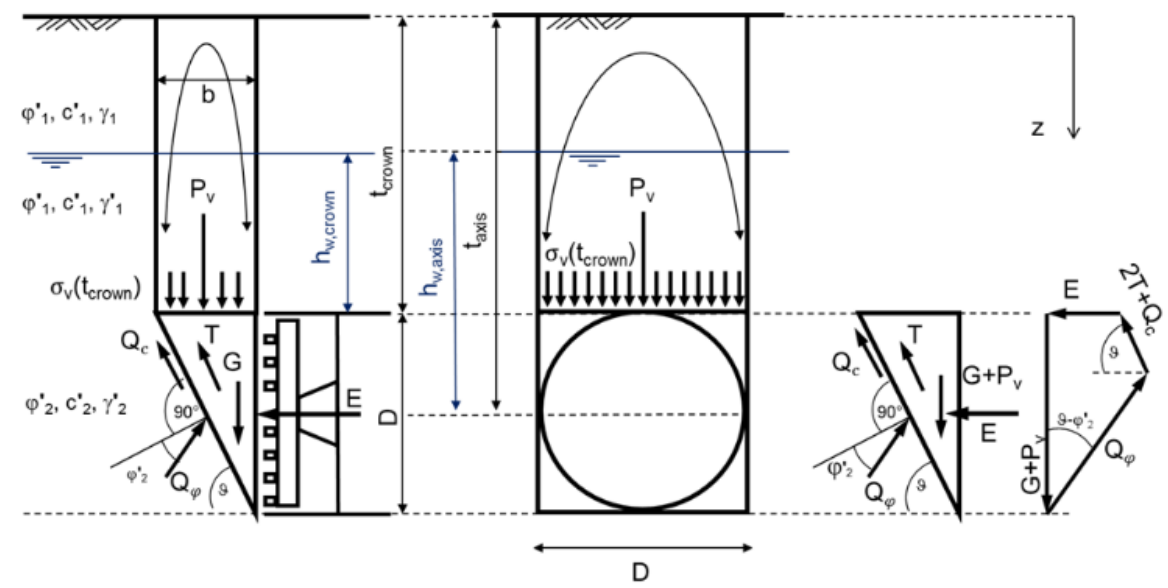

where $E_{r e}$ : support force due to earth pressure, $G:$ weight of the wedge, $P_{v}:$ vertical load from the soil prism, $T:$ shear force on the vertical slip surface, $\vartheta$ : sliding angle, $\varphi^{\prime}$ : friction angle of the soil, $c$ : cohesion of the soil, $D:$ e shield diameter, $Q$ : shear force on the inclined surface, $\gamma:$ unit weight of the soil

Figure 2 Forces on the sliding wedge mechanism (Anagnostou, 2012)

The required support pressure can be calculated using Equation 1. The equilibrium condition is based on variations in the sliding angle of the wedge $(\vartheta)$, which determines the support force and which has an impact on the highest support face pressure (Emax,re).

$$
E_{r e}(\vartheta)=\frac{\left(G+P_{v}\right) \cdot\left(\sin (\vartheta)-\cos (\vartheta) \cdot \tan \left(\varphi^{\prime}{ }_{2}\right)\right)-2 \cdot T-c^{\prime}{ }_{2} \frac{D^{2}}{\sin (\vartheta)}}{\sin (\vartheta) \cdot \tan \left(\varphi^{\prime}{ }_{2}\right)+\cos (\vartheta)}
$$

The vertical load force from the soil prism on the wedge $\left(P_{v}\right)$ is calculated using Equation 2 by multiplying the area on the top of the wedge by the vertical effective stress acting on the wedge.

$$
P_{v}=A \cdot \sigma_{v}\left(t_{\text {crown }}\right)=D \cdot \frac{D}{\tan \vartheta_{\text {crit }}} \cdot \sigma_{v}\left(t_{\text {crown }}\right)
$$

where $\sigma_{v}\left(t_{\text {crown }}\right)$ is the vertical surcharge from the prism on the wedge, $A$ is the crosssectional area of the silo $\left(\mathrm{m}^{2}\right), \vartheta_{\text {crit }}$ is the sliding angle of the wedge in the highest support face pressure.

Vertical stress at elevation $\mathrm{z}$ can be calculated considering the soil arch, which is taking into account the total weight of the soil above the tunnel if the overburden is less than twice the tunnel diameter (Equation 3) and using Equation 4 if the overburden is otherwise. The coefficients of lateral earth pressure from recent studies i.e. Kirsch and Kolymbas (2005), and Girmscheid (2008) are shown in Table 1.

$$
\begin{gathered}
\sigma_{v}(z)=\gamma_{1, a v} \cdot z+\sigma_{S} \text { for } t_{\text {crown }} \leq 2 \cdot D \\
\sigma_{v}(z)=\frac{\frac{A}{U} \cdot \gamma_{1, a v}-c^{\prime}{ }_{1}}{K_{1} \cdot \tan \left(\varphi^{\prime}{ }_{1}\right)}\left(1-e^{-\frac{U}{A} \cdot K_{1} \cdot \operatorname{zt} \tan \left(\varphi^{\prime}{ }_{1}\right)}\right)+\sigma_{s} \cdot e^{-\frac{U}{A} \cdot K_{1} \cdot z \cdot \tan \left(\varphi^{\prime}{ }_{1}\right)} \text { for } t_{\text {crown }}>2 D
\end{gathered}
$$

where $\sigma_{v}(z)$ is the vertical stress at elevation $\mathrm{z}\left(\mathrm{kN} / \mathrm{m}^{2}\right), \gamma_{1, a v}$ is the average soil unit weight in the overburden area $\left(\mathrm{kN} / \mathrm{m}^{3}\right), \mathrm{z}$ is the vertical elevation from the surface $(\mathrm{m})$, $t_{\text {crown }}$ is the overburden height (m), $\sigma_{s}$ is the surcharge on the surface (traffic load) $\left(\mathrm{kN} / \mathrm{m}^{2}\right), U$ is the circumference length of the silo $(\mathrm{m}), K_{1}$ is the coefficient of lateral earth pressure within the silo, $k_{0}$ is the coefficient of earth pressure at rest, $k_{a}$ is the coefficient of active lateral earth pressure, $k_{p}$ is the coefficient of passive lateral earth pressure. 
Table 1 Coefficients of lateral earth pressure $\left(K_{1}\right)$

\begin{tabular}{cc}
\hline Studies & Coefficients of lateral earth pressure \\
\hline $\begin{array}{c}\text { Kirsch and Kolymbas (2005) } \\
\text { Girmscheid (2008) }\end{array}$ & $K_{1}=k_{0}=1-\sin \left(\vartheta^{\prime}{ }_{1}\right)$ \\
\hline
\end{tabular}

The weight of the wedge $(G)$ is calculated using Equation 5, while the shear resistance force is calculated according to friction force and cohesion force (Equation 6).

$$
\begin{gathered}
G=\frac{1}{2} \cdot \frac{D^{3}}{\tan \left(\vartheta_{c r i t}\right)} \cdot \gamma_{2, a v} \\
T=T_{R}+T_{C}
\end{gathered}
$$

where $D$ is the tunnel diameter (m), $\gamma_{2, a v}$ is the average soil unit weight in the tunnel face area $\left(\mathrm{kN} / \mathrm{m}^{3}\right), T$ is the shear resistance force on the vertical triangular plane of the wedge $(\mathrm{kN}), T_{R}$ is the friction shear resistance force $(\mathrm{kN}), T_{c}$ is the cohesion shear resistance force $(\mathrm{kN})$.

Girmscheid (2008), DIN 4126 (2013), and Anagnostou and Kovari (1994) proposed that the same stress was simultaneously present next to the top level of the wedge, next to the vertical plane of the wedge, and at the bottom of the wedge, which can be calculated using Equation 7. Kirsch and Kolymbas (2005) proposed that the vertical stress at the top of the wedge was equal to the stress next to the wedge and linearly increases along the vertical plane according to the unit weight of the soil, which can be calculated using Equation 8.

$$
\begin{gathered}
T_{R, 1}=\tan \left(\varphi^{\prime}{ }_{1}\right) \cdot K_{2} \cdot\left(\frac{D^{2} \cdot \sigma_{v}(t)}{3 \cdot \tan \left(\vartheta_{c r i t}\right)}+\frac{D^{3} \cdot \gamma_{2}}{6 \cdot \tan \left(\vartheta_{c r i t}\right)}\right) \\
T_{R, 2}=\tan \left(\varphi^{\prime}{ }_{2}\right) \cdot K_{2} \cdot\left(\frac{D^{2} \cdot \sigma_{v}(t)}{2 \cdot \tan \left(\vartheta_{c r i t}\right)}+\frac{D^{3} \cdot \gamma_{2}}{6 \cdot \tan \left(\vartheta_{c r i t}\right)}\right) \\
K_{2}=\frac{k_{0}+k_{a}}{2}
\end{gathered}
$$

\subsection{Numerical Modelling}

Numerical modelling using the finite element method is usually used to evaluate the soil structure interaction between the TBM and the surrounding soil. The German Tunnelling Committee (ITA-AITES, 2016) recommended 3D numerical modelling with stage construction to evaluate the tunnel excavation phase (Figure 3). Sometimes, 2dimensional (2D) numerical modelling is used to evaluate face stabilization that is perpendicular to the longitudinal excavation direction. Nevertheless, the 2D model cannot give an accurate result because it does not evaluate the tunnel shape effect. In the study discussed in this paper, an evaluation was conducted using shell elements before the tunnel excavation began to determine the acting face pressure at the shell element. Comparative evaluations according to the actual face pressure were then conducted to see the effectiveness of this concept in the design phase. 


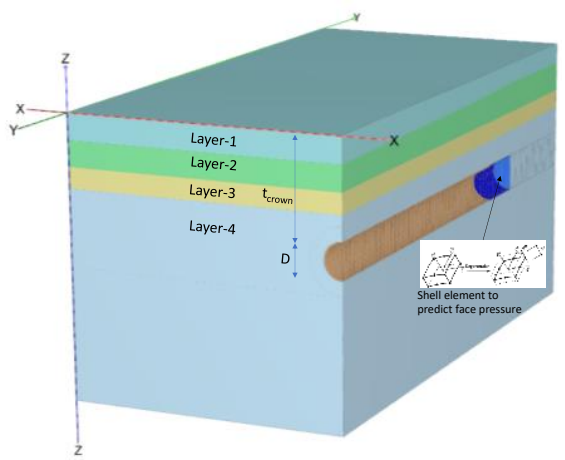

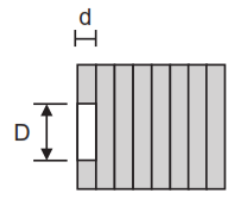

$\mathrm{i}-1$

a. 3D Numerical Modelling

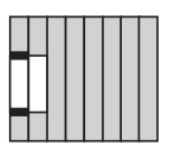

i

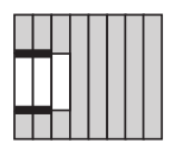

$\mathrm{i}+1$

b. Side view

Figure 3 Numerical modelling schemes for the 3D model

Since plates or a shell model in the 3D finite element method (Plaxis, 2017) can only display normal stress, shear stress, and bending moments according to the local axis, as seen in Figure 4, circular pressure can be calculated using Equation 10.

$$
M r=\frac{w}{16}\left[a^{2}(1+v)-r^{2}(3+v)\right]
$$

where $M r$ is the radial moment $(\mathrm{kN} / \mathrm{m}), a$ is the slab radius $(\mathrm{m}), v$ is the Poisson's ratio, $r$ is the any section distance $r$ from the origin $(\mathrm{m}), w$ is the intensity of uniformly distributed load $\left(\mathrm{kN} / \mathrm{m}^{2}\right)$.

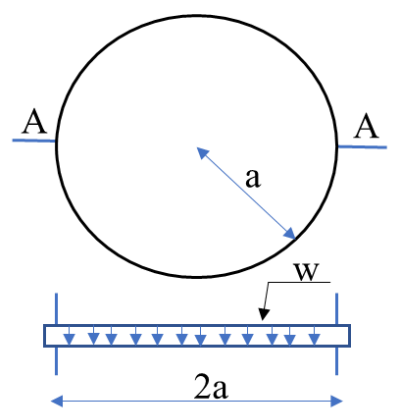

Figure 4 Circular slab for the uniformly distributed load model (Ramchandra and Gehlot, 2018)

\subsection{Soil Stratification and Parameters}

According to the boring logs for tunnel alignment that were compiled in 2010, 2016, and 2017, soil stratifications in the research area are defined in accordance with ASTM D2487-11 (2011), as shown in Figure 5. Tunnel construction was predicted to be going through hard silty sand and below the ground water level. The soil parameters discussed in this paper are based on laboratory testing results that were optimized using a soil test facility. The empirical correlations presented in this paper refer to a publication by Lim et al. (2010), i.e., the compression index, $\lambda$, is equal to $C_{c} / 2.303$ and the swelling index, $\mathrm{K}$, is equal to $C_{s} / 2.303$ where the ratio of $C_{s} / C_{c}$ or $\mathrm{K} / \lambda$ is about $0.09-0.15$. The pure Poisson's ratio can be assumed to be 0.2 , as suggested in the Plaxis manual (Plaxis, 2017). Calvello and Finno (2004) suggested stiffness parameters for the Hardening Soil Model (HSM) as 
$E_{50}^{r e f}=1 / 3 E_{u r}^{r e f}$ and $E_{\text {oed }}^{r e f}=0.7 E_{50}^{r e f}$. HSM and the Soft Soil Model (SSM) are the soil constitutive models used in the 3D finite element model, as seen in Table 2 and Table 3, respectively. The Over-Consolidation Ratio (OCR) is defined as the highest stress divided by the current stress. Soil that is currently experiencing its highest stress is said to be normally consolidated and has an OCR of 1 . In numerical modelling, it is necessary to consider the coefficient of strength reduction in the interface (Rinter) in order to correctly simulate moving contact between the structure and the soil. In this paper, Rinter $=0.6$ is used in the soil modelling.

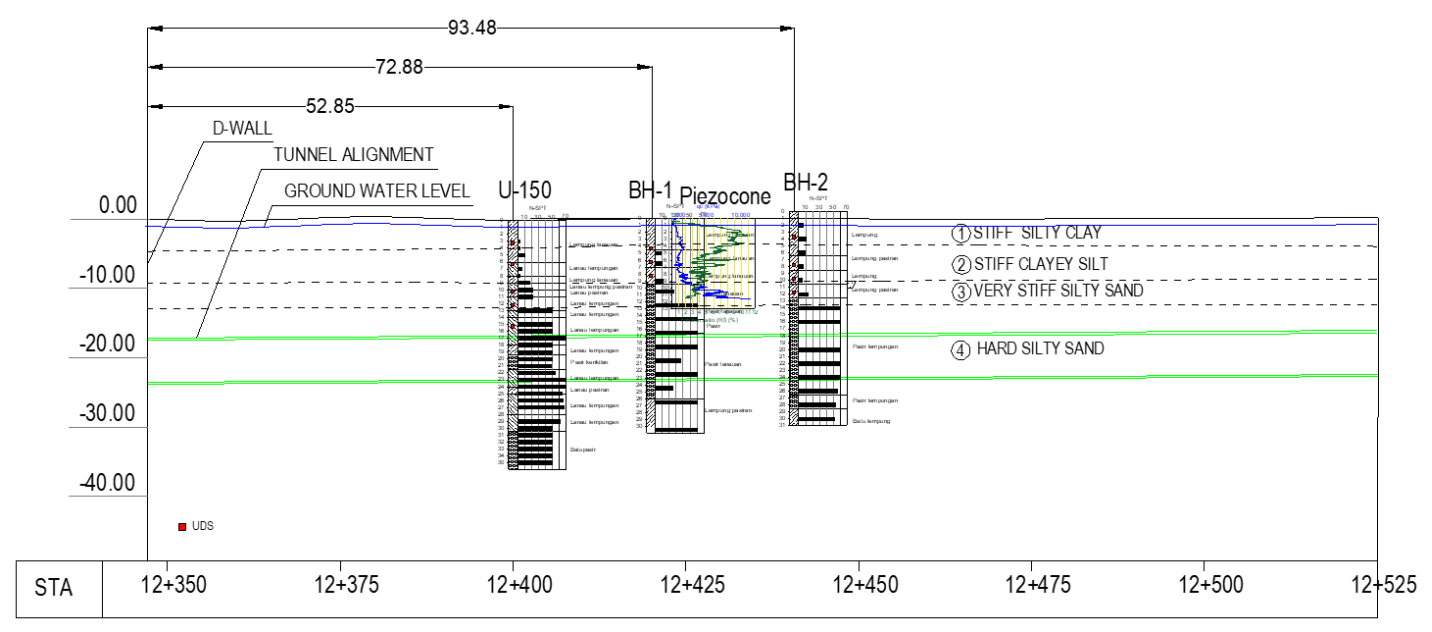

Figure 5 Soil stratification in relation to the tunnel alignment

Table 2 Hardening Soil Model (HSM) parameters

\begin{tabular}{|c|c|c|c|c|c|c|c|c|c|c|}
\hline Name & $\begin{array}{l}\text { Depth } \\
\text { (m) }\end{array}$ & Description & $\begin{array}{l}\text { N-SPT } \\
\text { (mean) }\end{array}$ & $\begin{array}{c}\gamma \\
\left(\mathrm{kN} / \mathrm{m}^{3}\right)\end{array}$ & $\begin{array}{c}c^{\prime} \\
(\mathrm{kPa})\end{array}$ & $\begin{array}{l}]^{\prime} \\
\left({ }^{\circ}\right)\end{array}$ & OCR & $\begin{array}{c}\text { Secant } \\
\text { stiffness, } \\
\text { E}_{50}(\mathrm{kPa})\end{array}$ & $\begin{array}{c}\text { Unload/ } \\
\text { reload } \\
\text { stiffness, } \\
\text { Eur }(\mathrm{kPa}) \\
\end{array}$ & $\begin{array}{l}\text { Oedometer } \\
\text { stiffness, } \\
\text { Eoed }(\mathrm{kPa})\end{array}$ \\
\hline Layer 1 & $0.00-4.60$ & Stiff silty clay & 5 & 15.48 & 11 & 28.2 & 4.7 & 22,000 & 66,000 & 15,400 \\
\hline Layer 2 & $4.60-9.20$ & $\begin{array}{l}\text { Stiff clayey } \\
\text { silt }\end{array}$ & 6 & 15.10 & 11 & 28.2 & 1.8 & 18,000 & 54,000 & 12,600 \\
\hline Layer 3 & $9.20-12.87$ & $\begin{array}{l}\text { Very stiff } \\
\text { silty sand }\end{array}$ & 11 & 15.05 & 13.4 & 27.7 & 1.2 & 19,000 & 57,000 & 13,300 \\
\hline Layer 4 & $12.87-50.00$ & $\begin{array}{c}\text { Hard silty } \\
\text { sand }\end{array}$ & 45 & 17.00 & 1 & 30 & 1 & 35,000 & 105,000 & 24,500 \\
\hline
\end{tabular}

Table 3 Soft Soil Model (SSM) parameters

\begin{tabular}{cccccccccc}
\hline Name & Depth $(\mathrm{m})$ & Description & $\begin{array}{c}\text { N-SPT } \\
\text { (mean) }\end{array}$ & $\begin{array}{c}\gamma \\
\left(\mathrm{kN} / \mathrm{m}^{3}\right)\end{array}$ & $\begin{array}{c}c^{\prime} \\
(\mathrm{kPa})\end{array}$ & $\begin{array}{c}\text { 早 } \\
(\mathrm{o})\end{array}$ & OCR & $\lambda$ & $\mathrm{K}$ \\
\hline Layer 1 & $0.00-4.60$ & Stiff silty clay & 5 & 15.48 & 11 & 28.2 & 4.7 & 0.0233 & 0.0047 \\
Layer 2 & $4.60-9.20$ & Stiff clayey silt & 6 & 15.10 & 11 & 28.2 & 1.8 & 0.0210 & 0.0021 \\
Layer 3 & $9.20-12.87$ & Very stiff silty sand & 11 & 15.05 & 13.4 & 27.7 & 1.2 & 0.0370 & 0.0037 \\
Layer 4 & $12.87-50.00$ & Hard silty sand & 45 & 17.00 & 1 & 30 & 1 & 0.00046 & 0.000046 \\
\hline
\end{tabular}

The tunnel excavation phase in the 3D finite element method is simulated according to the excavation rate in a real construction sequence, i.e., $1.5 \mathrm{~m}$ for each tunnel lining segment during tunnel construction. The tunnel lining parameters used in the modelling are presented in Table 4. 
Table 4 Tunnel lining parameters

\begin{tabular}{ccccccc}
\hline Name & $\begin{array}{c}\text { Tunnel inner } \\
\text { diameter }(\mathrm{m})\end{array}$ & $\begin{array}{c}\text { Tunnel lining } \\
\text { thickness }(\mathrm{m})\end{array}$ & $\begin{array}{c}\text { Material } \\
\text { model }\end{array}$ & $\begin{array}{c}\gamma \\
\left(\mathrm{kN} / \mathrm{m}^{3}\right)\end{array}$ & $\begin{array}{c}\mathrm{E} \\
(\mathrm{kPa})\end{array}$ & $v$ \\
\hline Lining & 0.60 & 0.25 & Linear Elastic & 24 & $33,000,000$ & 0.15 \\
\hline
\end{tabular}

\subsection{Statistical Evaluation}

Coefficient of variation (COV) is used to describe the variations in the evaluation results from different populations ( $\mathrm{Liu}, 2012$ ). The bias value is used to measure and evaluate the relative dispersion data, which is equal to the ratio between the standard deviation and the mean (Equation 11) for the entire face pressure calculation dataset in comparison to the actual measurement by the soil pressure gauge. A bias value greater than 1 indicates that the calculated value is smaller than the actual measurement, while COV should be near 0 .

$$
\operatorname{COV}=\frac{\sigma}{\mu}
$$

where $\sigma$ is the standard deviation, and $\mu$ is the mean value.

\section{Results and Discussion}

\subsection{Analytical and Finite Element Method Modelling Results}

An analytical evaluation was conducted using the limit equilibrium trial and error method to obtain the critical equilibrium condition in accordance with the variations in the sliding angle of the wedge $(\vartheta)$, which determines the support force in the highest, lowest, and mean value of support face pressure along the tunnel crown alignment, i.e., Emax crown, Emin crown, and Emean crown (Figure 6). Face support pressure is influenced by the overburden height, which is indicated by the face pressure variations along the tunnel length. The influence of the arching effect was also evaluated to determine which of the following equations give the closest result to the actual pressure. The COV for the calculation without the arching effect is smaller than those for the calculation with the arching effect (Figure 7). Those findings indicate that excluding the arching effect in the calculation gives a better result than including it, as described in Section 2.4. The actual face support pressure stress seems to meet the upper boundary of the maximum stress according to the analytic calculation.

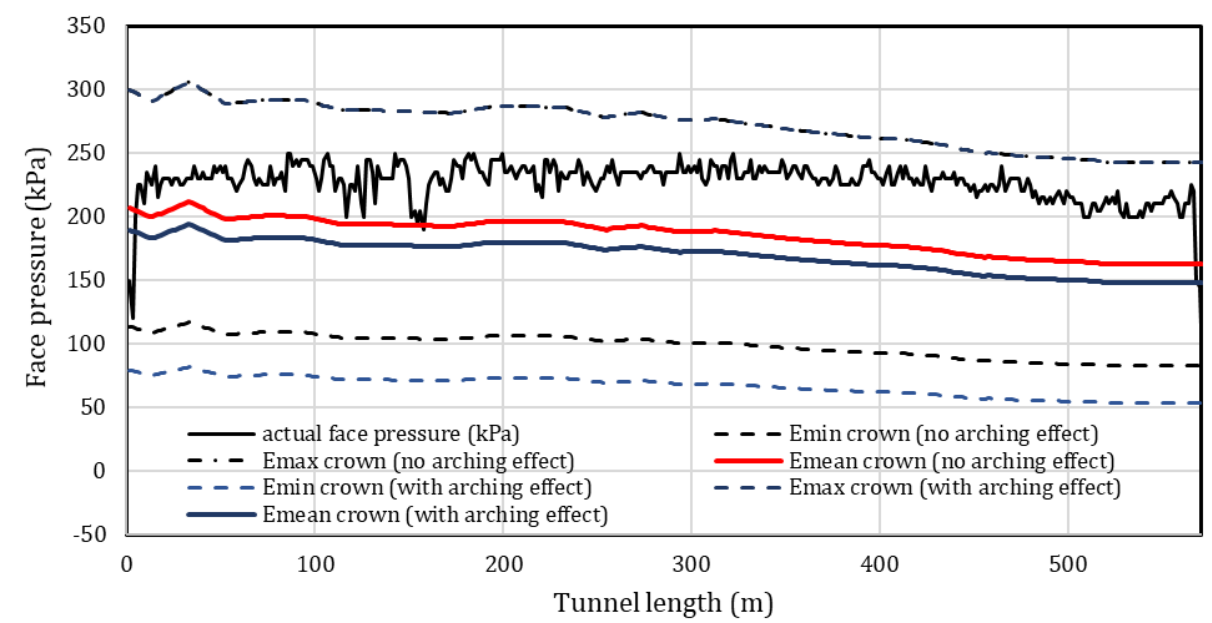

Figure 6 The arching effect evaluation 


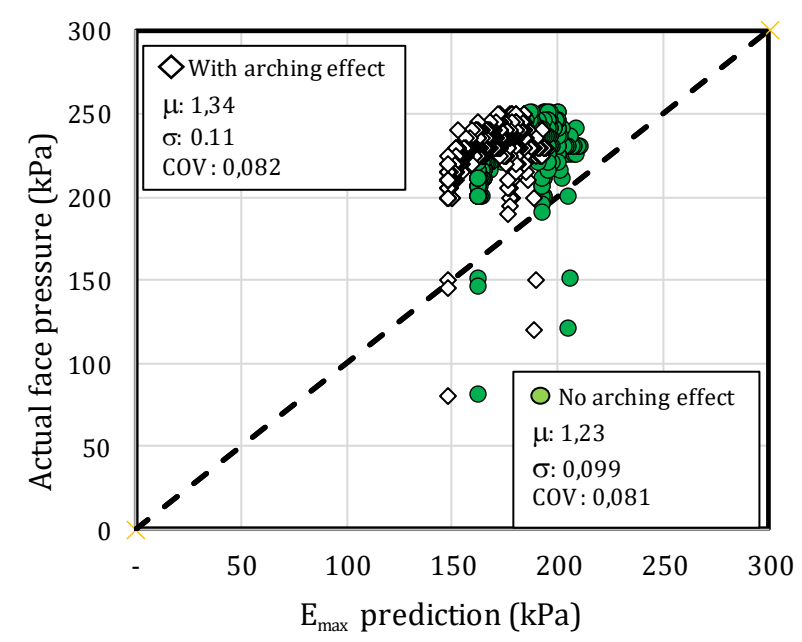

Figure $7 \mathrm{COV}$ and bias evaluation between the limit equilibrium measurement and the actual measurement

Numerical calculation using Plaxis 3D was conducted applying a construction stage to each of the excavation phases, and the shell elements placed in front of the excavation face were monitored for each step, as shown in Figure 8. The thickness of shell elements is fixed at $0.45 \mathrm{~m}$ according to thickness of the cutterhead used in the MRTJ project and the shell model parameters (Table 5).

Table 5 Shell model parameters

\begin{tabular}{cccccc}
\hline Name & Shell thickness $(\mathrm{m})$ & Material model & $\gamma\left(\mathrm{kN} / \mathrm{m}^{3}\right)$ & $\mathrm{E}(\mathrm{kPa})$ & $v$ \\
\hline Lining & 0.45 & Isotropic elastic & 78 & $2,000,000$ & 0.15 \\
\hline
\end{tabular}

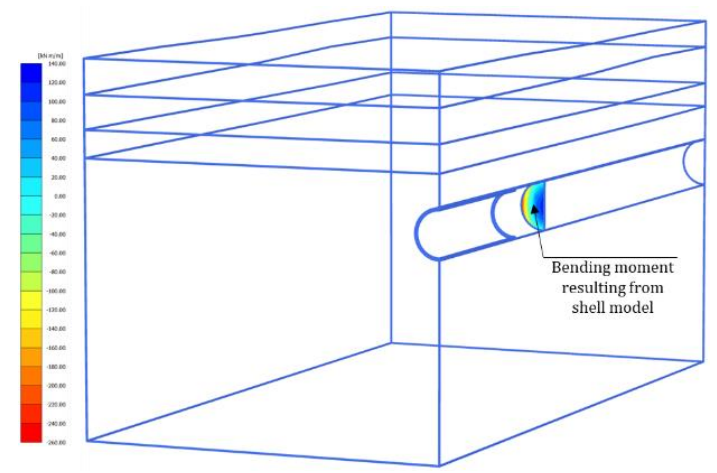

Figure 8 Face pressure acting on the shell element

A comparison of the shell element pressure resulting from the bending moment finite element modelling and the actual face support pressure is shown in Figure 9. The results for the HSM and the SSM are close; unfortunately, the finite element method measurement for face pressure was lower than the actual face pressure, which is also indicated by the bias mean values and COV (Figure 10). However, at the early stage of tunnel construction, the face pressure and actual pressure are perfectly matched when using the finite element method, which probably indicates the balance state condition at the tunnel face. ZTV-ING (2012) stated that calculations of the support pressure deviations for an EPB tunnel must be considered to be $+/-30 \mathrm{kPa}$. After the second phase excavation of numerical modelling 
for face pressure, in which $+80 \mathrm{kPa}$ is added, the face pressure measurement is similar to the actual pressure measurement (Figure 10). The additional load could be different depending on the elevation of the ground water level, the soil condition, and the overburden pressure.

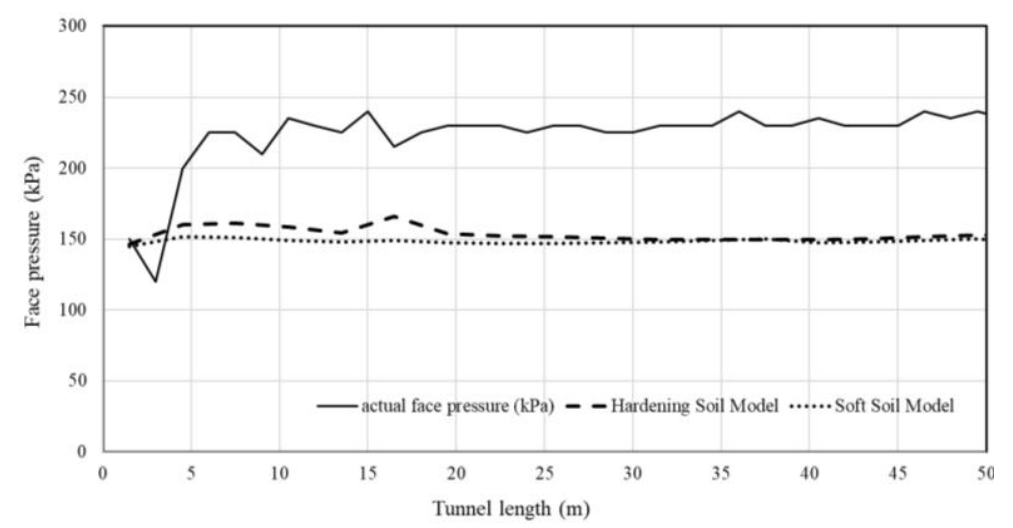

Figure 9 Comparison of the actual face support pressure and prediction pressure based on numerical models

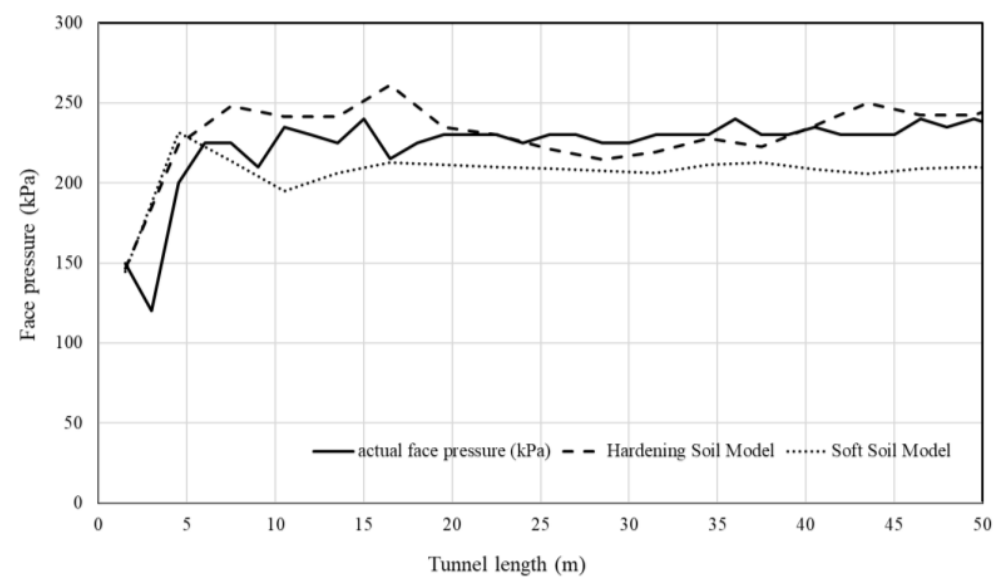

Figure 10 Comparison of the actual face support pressure and prediction pressure based on numerical models with $+80 \mathrm{kPa}$

\section{Conclusions}

Evaluation of the effectiveness of the limit equilibrium method to predict the mean value face support pressure and the upper and lower perimeters for tunnel construction yielded a good result; however, the initial mean pressure is relatively higher than the face pressure measured when using a TBM pressure gauge. Overall, the face pressure results using the shell model of the finite element method are lower than the actual pressure measurements; yet, at the early stage of tunnel construction, the face pressure results perfectly match the actual measured pressure at the tunnel face. This result probably indicates the balance state condition at the tunnel face, and the addition of $80 \mathrm{kPa}$ after the second phase of excavation could indicate the need for greater face pressure to ensure TBM movement. 


\section{Acknowledgements}

The author would like to acknowledge the Institute of Road Engineering, Ministry of Public Works, the Research Group of Geotechnical Engineering, Department of Civil Engineering, Faculty of Civil and Environmental Engineering, and the Institute for Research and Community Services (LPPM) of Bandung Institute of Technology.

\section{References}

Anagnostou, G., Kovari, K., 1994. The Face Stability in Slurry-shield-driven Tunnels. Tunnelling and Underground Space Technology, Volume 9(2), pp. 165-174

Anagnostou, G., 2012. The Contribution of Horizontal Arching to Tunnel Face Stability. Geotechnik, Volume 35(1), pp. 34-44

American Society for Testing and Meterials (ASTM D2487-11), 2011. Standard Practice for Classification of Soils for Engineering Purposes. ASTM International, West Conshohocken, United States of America

Calvello, M., Finno, R.J., 2004. Selecting Parameters to Optimize in Model Calibration by Inverse Analysis. Computer and Geotechnics, Volume 31, pp. 410-424

Deutsches Institut fur Normung (DIN 4126), 2013. Nachweis der Standsicherheit von Schlitzwänden (Stability Analysis of Diaphragm Walls), Beuth Verlag GmbH, Berlin

Girmscheid, G., 2008. Baubetrieb und Bauverfahren im Tunnelbau (Construction Operation and Construction Methods in Tunnel Construction). Ernst und Sohn Verlag, Berlin

International Tunneling Association-Association Internationale Des Tunnels Et De L Espace Souterrain (ITA-AITES), 2016. Recommendations for Face Support Pressure Calculations for Shield Tunneling in Soft Ground. German Tunneling Committee, Koln, Germany

Kirsch, A., Kolymbas, D., 2005. Theoretische Untersuchung zur Ortsbruststabilität (Theoretical Investigation of Face Stability). Bautechnik, Volume 82(7), pp. 449-456

Lim, A., Ou, C-Y., Hsieh, P-G., 2010. Evaluation Clay of Constitutive Models for Analysis of Deep Excavation under Undrained Conditions. Journal of GeoEngineering, Volume 5(1), pp. $9-20$

Liu, S., 2012. Confidence Interval Estimation for Coefficient of Variation. Master of Science Thesis, Georgia State University, Atlanta, United States of America

Plaxis, 2017. Part 3: Plaxis Material Models Manual. Delf University of Technology \& Plaxis B.V., The Netherlands

Ramchandra, Gehlot, V., 2018. Limit State Design of Concrete Structures. Scientific Publishers, Jodhpur, India

Shimizu-Obayashi-Wijaya Karya-Jaya Konstruksi (SOWJ), 2015. Jakarta MRT CP104/105 construction progress. Technical Meeting Material, Wijaya Karya Persero, Jakarta

Zusätzliche Technische Vertragsbedingungen und Richtlinien für Ingenieurbauten (ZTVING) 2012. Teil 5 (Part 5): Tunnelbau (Tunnel Construction). Bundesanstalt für Strassenwesen (Federal Highway Research Institute), Koln, Germany 